\title{
Epidemiology of Ancylostoma spp. in the endangered Iberian lynx (Lynx pardinus) in the Doñana National Park, south-west Spain
}

\author{
J. Vicente ${ }^{1,2 *}$, F. Palomares ${ }^{3}$, R. Ruiz de Ibañez ${ }^{2}$ and J. Ortiz ${ }^{2}$ \\ ${ }^{1}$ Instituto de Investigación en Recursos Cinegéticos (CSIC/UCLM), \\ PO Box 535, E-13080 Ciudad Real, Spain: ${ }^{2}$ Parasitología y Enfermedades \\ Parasitarias, Departamento Patología Animal, Facultad de Veterinaria de \\ Murcia, Campus de Espinardo, 30100 Murcia, Spain: ${ }^{3}$ Department of \\ Applied Biology, Estación Biológica de Doñana (CSIC), \\ Avda. María Luisa s/n, 41013 Sevilla, Spain
}

\begin{abstract}
The epidemiology of Ancylostoma spp. was studied in the endangered Iberian lynx (Lynx pardinus) in the Doñana National Park, south-west Spain. Faecal samples were collected throughout a complete annual cycle (August 1997 to September 1998). The overall egg prevalence of Ancylostoma spp. was 57.8\%. The pattern of abundance of Ancylostoma spp. eggs in faeces was overdispersed. Juvenile lynx demonstrated a statistically higher prevalence and abundance of Ancylostoma spp. than in adults. These levels of egg output (maximum 21195 epg), as previously reported in free ranging large felid cubs, could be close to disease involvement. The potential pathogenicity of hookworms and the influence of individual and ecological factors on hookworm transmission in the Iberian lynx from the Doñana National Park population are discussed.
\end{abstract}

\section{Introduction}

The implications of natural diseases in large cats pose a general conservation problem because of their threatened status and can even lead to preventive or therapeutic management in free-living animals (Roelke et al., 1985). The Iberian lynx (Lynx pardinus) is a medium sized carnivore species exclusive to the south-west of the Iberian Peninsula. According to the World Conservation Union (IUCN, Nowell \& Jakson, 1996), L. pardinus is considered to be the most endangered feline species in the world, with an estimated number of not more than 300 individuals, distributed in several isolated populations (Delibes et al., 2000). One of the two main populations, and the best known, is in the Doñana National Park, where ecological studies have been carried out for several years (Palomares et al., 1996). This Iberian lynx population comprises about 40 individuals occupying a fragmented

*Fax: +34 926225184

E-mail: jvicente@irec.uclm.es landscape and isolated from other lynx populations, which could make it theoretically non-viable (Gaona et al., 1998). Postnatal mortality is known to be around 33\%, the reasons for which are undetermined (F. Palomares et al., unpublished data).

There is little available information about parasites and infectious diseases of the Iberian lynx (Delibes et al., 2000). Faecal examination for parasite infective stages is a valuable alternative to obtaining host samples (FestaBianchet, 1991; Müller-Graf et al., 1999), especially for rare and endangered animals where information from parasite studies is important for management and conservation purposes.

The ecology of helminth parasites, including hookworms, has been reported in several lynx species in the world, mainly in North American bobcats (Lynx rufus) and Canadian lynxes (Lynx canadensis) (Stone \& Pence, 1978; Smith et al., 1985; Mclaughlin et al., 1993). Ancylostoma tubaeforme, a cosmopolitan and specific hookworm in Felidae, has previously been reported in the Iberian lynx (Torres et al., 1998). Ancylostoma 
tubaeforme has also been found in wild cats (Felis silvestris), wild cat-domestic cat hybrids (Miquel et al., 1994) and stray domestic cats (Calvete et al., 1998) in the Iberian Peninsula. Clinical signs in wild free-ranging felids have been associated with ancylostomosis by perinatal transmission in American large cats (Roelke et al., 1985; Dunbar et al., 1994).

The objectives of the present study were to evaluate: (i) the epidemiology of Ancylostoma spp. in the Iberian lynx population in the Doñana National Park through a study of faecal samples; and (ii) the effect of natural infections of hookworms on lynx in view of the disease implications of these parasites in comparable populations of endangered feline species. This investigation would provide information on a helminth pathogen which could potentially be involved in the neonatal survival of the Iberian lynx.

\section{Materials and methods}

\section{Field site}

The study was carried out in the Donana National Park, a $550 \mathrm{~km}^{2}$ reserve on the Atlantic coast in southeastern Spain, on the Guadalquivir river mouth $\left(37^{\circ} 09^{\prime} \mathrm{N}\right.$, $\left.06^{\circ} 26^{\prime} \mathrm{W}\right)$. The predominant habitats are marshes, mediterranean scrublands and sand dunes. Apart from stray cats, nine different carnivore species coexist in Doñana. The Iberian lynx is the heaviest, weighing $10-12 \mathrm{~kg}$ (Palomares et al., 1996).

The study area is located in Coto del Rey, in the north of Doñana National Park and is characterized by scrubland patches of Pistacia lentiscus and Halimium halimifolium with scattered Quercus ruber trees and Fraxinus angustifolius flanking seasonal streams.

The climate is mediterranean with Atlantic influence. The dry season typically starts in May and lasts until September and is characterized by high temperatures (e.g. monthly maximum mean temperature of $32.7^{\circ} \mathrm{C}$ in August 1997). Most yearly rains are concentrated in the wet season, which normally begins by September and continues, with considerable variations, until April, with mild temperatures (e.g. monthly minimum mean temperature of $7.4^{\circ} \mathrm{C}$ in February 1998). These rainfall and temperature data were used to classify each season with precision, the dry season extending from 15 May to 15 September and the wet season for the remainder of the year.

\section{Lynx populations}

Three lynx foci were distinguished by Palomares et al. (1991) in the metapopulation of Doñana National Park. The lynx subpopulation from Coto del Rey contains the highest density in the Doñana area and is probably the highest worldwide. The lynx population of the study area consisted of three resident lynx couples, their offspring (three cubs as mean) and occasional wandering individuals. Faecal samples were identified as belonging to: (i) juvenile ( $\leq 9$ months) or adult lynx ( $>9$ months); and (ii) dry or wet seasons (table 1 ).

\section{Collection of faecal samples}

Fresh faecal samples from Coto del Rey were collected within $24 \mathrm{~h}$ after their deposition. Sampling was carried out throughout the period from August 1997 to September 1998 in conjunction with an ecological study on lynx in the same area. The collection and precise assignation to juvenile (all juvenile samples but one were less than 6 months old according to birth date) or adult classes in the field were possible when animals were radiolocated or their latrines were visited. Immobilization of trapped lynx with a combination of ketamine hydrochloride and xylazine hydrochloride (Ferreras et al., 1994) allowed the collection of faecal material from known individuals. Faeces were weighed and mixed with an equal volume of $10 \%$ buffered formalin until analysed in the laboratory.

\section{Laboratory analysis}

Analyses were performed using a flotation technique in Seather's sacharose solution with a specific gravity of 1.275 (Georgi \& Georgi, 1990). Individual faecal egg counts were performed using McMaster cameras. Faeces were dehydrated in a stove at $100^{\circ} \mathrm{C}$ so that eggs per gram (epg) were always expressed in relation to dehydrated faeces. Helminth eggs were identified according to their morphology (Patton et al., 1986; Georgi \& Georgi, 1990; Patton \& Rabinowitz, 1994; Müller-Graf, 1995) and linear lengths with a calibrated eyepiece micrometer.

The digestive tract of an adult road-killed female lynx from the Doñana population was examined for helminths. Hookworms were removed and preserved in $70 \%$ ethanol, cleared in lactophenol and morphologically examined under a light microscope. Hookworn specimens were deposited in the Laboratory of the Unidad Docente de Parasitología y Enfermedades Parasitarias del Departamento de Patología Animal de la Universidad de Murcia (ref. A. t. 01/1998).

\section{Statistical analysis}

The prevalence is defined as the number of faeces infected with eggs of Ancylostoma spp. related to all examined samples, and the mean abundance describes the mean number of eggs in a faecal sample related to both

Table 1. The prevalence (\% \pm S.E.) of Ancylostoma spp. eggs in faecal samples of Iberian lynx in the Doñana National Park, $1997 / 98$.

\begin{tabular}{|c|c|c|c|c|c|c|}
\hline & \multirow[b]{2}{*}{ Adults } & \multirow[b]{2}{*}{ Juveniles } & \multicolumn{2}{|c|}{ Dry season } & \multicolumn{2}{|c|}{ Wet season } \\
\hline & & & Adults & Juveniles* & Adults & Juveniles \\
\hline No. of faecal samples examined & 48 & 9 & 17 & & 31 & 9 \\
\hline Prevalence $(\%)$ & $50.0 \pm 3.6$ & 100.0 & $35.2 \pm 5.5$ & & $58.0 \pm 4.3$ & 100.0 \\
\hline
\end{tabular}

* No data available for juveniles in the dry season. 
infected and uninfected samples (Margolis et al., 1982). Standard errors for prevalences were estimated with the expression S.E. $(p)=p(1-p) / \mathrm{n}^{1 / 2}$ (Martin et al., 1987).

The following statistical analyses are based on egg counts. Host age and seasonal status were treated as variables with two classes respectively: (i) juveniles ( $\leq 9$ months) or adults ( $>9$ months); and (ii) collected during dry or wet season.

To test for significant differences in the faecal prevalence of eggs of Ancylostoma spp. between host age (in wet season) and season (in adults) classes, a Fisher two-tailed test was employed. To check if egg counts were normally distributed, they were contrasted with Kolmogorov-Smirnov test (K-S test). For faecal abundances, the significance of host age (in wet season) and season (in adults) were separately tested. For all comparisons the non parametric Mann-Whitney U-Test (M-W test) for two independent variables was used (Siegel, 1970). The level of significance was established at the $5 \%$, using the SPSS 10.0.6 program ( ${ }^{\circledR}$ SPSS Inc., 1999).

\section{Results}

\section{Parasite identification}

Thin-shelled and ellipsoidal-shaped eggs containing a morula in different segmented states were observed in coprological analyses. Eggs were initially classified as species of Ancylostoma, according to the morphology and linear measurements ( $\mathrm{n}=75)$ (egg size length: 57-63 $\mu \mathrm{m}$, mean: $56.6 \pm 3.2$ s.D.; width: $37-41 \mu \mathrm{m}$, mean: $38.6 \pm 3.0$ S.D.).

The post-mortem examination of a lynx carcass revealed the presence of nine nematode specimens in the small intestine. They were identified as A. tubaeforme (Burrows, 1956). Eggs from faeces were found to be morphologically similar to a sample of eggs from mature and gravid A. tubaeforme.

\section{Faecal infections}

The distribution of Ancylostoma spp. egg outputs was not normal $(P<0.05)$. The mean prevalence value in the faeces was $58.8 \pm 6.1$ S.E., with a mean abundance of $1218.9 \pm 3722.4$ S.D. epg. The abundance of eggs in faecal samples showed an overdispersion, with variance/mean ratio significantly greater than unity.

Table 2. The range and mean number of eggs of Ancylostoma spp. eggs in faecal samples from lynx in the Doñana National Park $1997 / 1998$

\begin{tabular}{lcc}
\hline & Mean no. of eggs \pm SD & Range (min-max) \\
\hline Adults & $307.3 \pm 790.2$ & $0-4372.0$ \\
Juveniles & $6081.0 \pm 7857.9$ & $36.9-21195.2$ \\
Dry season & $108.1 \pm 185.9$ & $0-577.3$ \\
$\quad$ Adults & & \\
$\quad$ Juveniles & & \\
Wet season & & \\
$\quad$ Adults & & \\
Juveniles & $6081.0 \pm 7857.9$ & $36.9-21195.2$ \\
\hline
\end{tabular}

* No data available for juveniles in the dry season.

\section{Seasonal levels of infection}

Hookworm eggs were widespread in the faeces of both adult $(58.09 \%)$ and juvenile $(100 \%)$ lynx during the wet season (table 1). Faecal samples from the juveniles showed statistically higher prevalences than those from the adults in the wet season $(P<0.05)$. With samples from adult lynx only, no significant difference in prevalence between the seasonal groups was found $(P>0.05)$.

Faecal abundances for season and host age groups are summarized in table 2 . There were no statistical differences between the dry (mean: $108.1 \pm 185.9$ S.D.) and wet seasons (mean: $416.5 \pm 961.8$ S.D.) when only adults were considered $(P>0.05)$. Juveniles shed significantly more epg (mean: $6081 \pm 7857.9$ S.D.) than adults (mean: $416.5 \pm 961.8$ S.D.) $(P<0.05)$ during the wet season.

\section{Discussion}

Morphological similarities were found between the eggs of Ancylostoma spp. from faecal samples and those from gravid $A$. tubaeforme females removed from a necropsied adult lynx, hence confirming the identification as A. tubaeforme. This species is the only hookworm previously reported in the Iberian lynx, and found in an individual from the Doñana National Park (Torres et al., 1998).

Ancylostoma tubaeforme is the most prevalent gastrointestinal parasite in faecal samples from our of study (J. Vicente, unpublished observations), while ascarids are the most prevalent parasites infecting the Iberian lynx in their current area of distribution (Torres et al., 1998). Introduced felids can be a new source of hookworms for an indigenous population, including exotic and potentially pathogenic parasite species (Roelke et al., 1985). Thus, from the point of view of Iberian lynx management, it is important to consider the special features concurring in the Doñana National Park, where Iberian lynx and wild cats coexist with stray cats, and the associated risks of parasite transmission and shared host-cycles.

Coprological results suggest that hookworms are widespread in this subset of Iberian lynx from the Doñana National Park. A mean faecal prevalence of $57.8 \%$ of Ancylostoma spp. is much higher than the coprological analysis $(22.2 \%)$ of Iberian lynx in central Spain (Rodriguez \& Carbonell, 1998). To our knowledge, only a higher prevalence (91.9\%) of Ancylostoma spp. eggs in faecal samples of free ranging wild felids has been reported in Lynx rufus from southern Texas (Mitchell \& Beasom, 1974).

The high density that the Iberian lynx reaches in the Doñana National Park, and especially in Coto del Rey, may favour infection and reinfection of direct cycle parasites. Parasitism by monoxenous parasites may be related to host density in wild mammal populations, including hookworms as potential indicators of densities in wild lynxes (Watson et al., 1981). Large prevalences of hookworm infections in wild felids have been found in social species such as African lion Panthera leo, (MüllerGraf, 1995; Bjork et al., 2000). However, the Iberian lynx does not demonstrate any social behavior (Ferreras et al., 1997). The overall faecal prevalence of $67.5 \%$ in the wet 
season in the Doñana National Park, being $58.0 \%$ for adults, is higher (Patton \& Rabinowitz, 1994) or similar (Patton et al., 1986) to that of hookworms in tropical wild felids. The climate in the area of the present study may influence the survival of free-living infective larvae, especially in dry and hot summer seasons.

The abundance data is difficult to interpret because of the scarcity of reference values in other wild felids. The abundance of eggs in the faecal samples showed an overdispersion. This agrees with an aggregated distribution of the parasite in the Iberian lynx from Coto del Rey (Shaw \& Dobson, 1995). A very small proportion of high counts and a majority of low counts may indicate differences in exposure or/and immunity between individuals (Müller-Graf et al., 1997).

Ancylostoma tubaeforme is widely spread among this subset of faecal samples in the Doñana National Park lynx population. The abundance of infection was significantly lower in adults than juveniles during the wet season. Also, there were no significant seasonal differences in abundance when only adult lynx were considered.

High faecal counts in juvenile lynx samples may reflect transient deficient immunity to hookworms and/or the effects of a larger exposure to infection. An early infection within the first days of life of the lynx, in the case of Ancylostoma spp., succeeds by the prenatal or transmammary route (Mclaughlin et al., 1993). A relatively lightly infected female lynx can produce heavily infected young (Mitchell \& Beasom, 1974). Moreover, an early exposure to A. tubaeforme infection may be related to the optimum microhabitat that natal dens could provide for maintaining infective larvae. Natal dens are repeatedly used by female Iberian lynx for breeding activity because they are a limited resource in Doñana (Fernández \& Palomares, 2000). This finding may favour oral or percutaneous transmission to juvenile lynx (Knowlton, 1972). In adult lynx, which show a high prevalence of infection, the reactivation of tissue larvae and development to adult worms, especially in periparturient periods, could contribute to maintenance the parasite population in the host intestine (Schad \& Page, 1982) as has been suggested in bobcats from southern Texas (Mitchell \& Beasom, 1974).

Mean abundances have not been described for eggs of Ancylostoma spp. in faeces in wild felid populations, but there are reports of egg counts associated with juvenile clinical ancylostomosis in wild free-ranging felids (Dunbar et al., 1994). Lower abundances of faecal outputs than we describe for juveniles Iberian lynx were found in a kitten of the Florida panther (Felis concolor coryi) with clinical parasitosis by Ancylostoma pluridentatum. In this clinical episode, egg shedding was monitored with a maximum of $936 \mathrm{epg}$ of fresh faeces (Dunbar et al., 1994) and a related increase of $4 \%$ to $24 \%$ of eosinophils was reported, decreasing to $6 \%$ after treatment. A juvenile recaptured lynx from the Doñana National Park has been reported to have high eosinophils levels (14\%), returning to a value similar to those of adult animals (1\%) when reaching adult age (Beltrán et al., 1991), which could coincide with the life span of Ancylostoma spp., estimated to be from 6 to 18 months (Kalkofen, 1987).

There is no direct evidence of clinical events or mortality in juvenile Iberian lynx due to ancylostomosis.
Nevertheless, the circumstances associated with this lynx population are similar to those of the endangered Florida panther. Ancylostomosis may play a role in neonatal morbidity and mortality in the population of Iberian lynx from the Doñana National Park, where individual losses are important. So, the study of parasite burdens and especially the possible clinical episodes relating to hookworms in cubs should be considered in future research for the purposes of management and conservation.

\section{Acknowledgements}

We thank J. Calzada, N. Fernández, M.A. López, E. Revilla and J.C. Rivilla for help with the collection of faecal samples, J.A. Blanco, C. Gortázar, P. Ferreras and E. Virgós for helpful comments. This research was supported by DGES (projects, PB94-0480 and PB971163), and Consejería de Medio Ambiente de la Junta de Andalucía.

\section{References}

Beltrán, J.F., Delibes, M., Recio, F. \& Aza, C. (1991) Hematological and serum chemical characteristics of the Iberian lynx (Lynx pardinus) in southwestern Spain. Canadian Journal of Zoology 69, 840-846.

Bjork, K.E., Averbeck, G.A. \& Stromberg, B.E. (2000) Parasites and parasite stages of free-ranging wild lions (Panthera leo) of northern Tanzania. Journal of Zoo and Wildlife Medicine 31, 56-61.

Burrows, R.B. (1956) Comparative morphology of Ancylostoma tubaeforme (Zeder, 1800) and Ancylostoma caninum (Ercolani, 1859). Journal of Parasitology 48, 715-718.

Calvete, C., Lucientes, J., Castillo, J.A., Estrada, R., Gracia, M.J., Peribañez, J. \& Ferrer, M. (1998) Gastrointestinal helminth parasites in stray cats from the mid-Ebro Valley, Spain. Veterinary Parasitology 75, 235-240.

Delibes, M., Rodríguez, A. \& Ferreras, P. (2000) Action plan for the conservation of the Iberian lynx in Europe (Lynx pardinus). Nature and Environment 111, Council of Europe Publishing.

Dunbar, M.R., Mclaughlin, G.S., Murphy, D.M. \& Cunningham, M.W. (1994) Pathogenicity of the hookworm Ancylostoma pluridentatum in a Florida panther (Felis concolor coryi) kitten. Journal of Wildlife Diseases 30, 548-551.

Fernández, N. \& Palomares, F. (2000) The selection of breeding dens by the Iberian lynx (Lynx pardinus): implications for its conservation. Biological Conservation 94, 51-61.

Ferreras, P., Aldama, J.J., Beltrán, J.F. \& Delibes, M. (1994) Immobilization of the endangered Iberian lynx with xylazine and ketamine-hydrochloride. Journal of Wildlife Diseases 30, 65-68.

Festa-Bianchet, M. (1991) Numbers of lungworm larvae in faeces of bighorn sheep: yearly changes, influence of host sex, and effects on host survival. Canadian Journal of Zoology 69, 547-554.

Gaona, P., Ferreras, P. \& Delibes, M. (1998) Dynamics 
and viability of a metapopulation of the endangered Iberian lynx (Lynx pardinus). Ecological Monographs 68, 349-370.

Georgi, J.R. \& Georgi, M.E. (1990) Parasitology for veterinarians. 5th edn. Philadelphia, Pennsylvania, W.B. Saunders Company.

Kalkofen, U.P. (1987) Hookworms of dogs and cats. Veterinary Clinics of North America: Small Animal Practice 17, 1341-1354.

Knowlton, F.F. (1972) Preliminary interpretations of coyote population mechanism with some management implications. Journal of Wildlife Management 36, 369-382.

Margolis, L., Esch, G.W., Holmes, J.C., Kuris, A.M. \& Schad, G.A. (1982) The use of ecological terms in parasitology (report of an Ad Hoc Committee of the American Society of Parasitologists). Journal of Parasitology 68, 131-133.

Martin, S.W., Meek, A.H. \& Willeberg, P. (1987) Veterinary epidemiology. Ames, Iowa State University Press.

Mclaughlin, G.S., Obstbaum, M., Forrester, D.J., Roelke, M.E. \& Brady, J.R. (1993) Hookworms of bobcats (Felis rufus) from Florida. Journal of the Helminthological Society of Washington 60, 10-13.

Miquel, J., Feliú, C., Torres, J. \& Casanova, J.C. (1994) Corología de las especies de nematodos parásitas de carnívoros silvestres en Cataluña (NE península Ibérica). Miscelánea Zoológica 17, 49-57.

Mitchell, R.L. \& Beasom, S.L. (1974) Hookworms in South Texas coyotes and bobcats. Journal of Wildlife Management 38, 455-458.

Müller-Graf, C.D.M. (1995) A coprological survey of intestinal parasites of wild lions (Panthera leo) in the Serengeti and the N'gorongoro Crater, Tanzania, East Africa. Journal of Parasitology 81, 812-814.

Müller-Graf, C.D.M., Collins, D.A., Packer, C. \& Woolhouse, M.E. (1997) Schistosoma mansoni infection in a natural population of olive baboons (Papio cynocephalus anubis) in Gombe Stream National Park, Tanzania. Parasitology 115, 621-627.

Müller-Graf, C.D.M., Woolhouse, M.E. \& Packer, C. (1999) Epidemiology of an intestinal parasite (Spirometra spp.) in two populations of African lions. Parasitology 118, 407-415.

Nowell, K. \& Jackson, P. (1996) Wild cats. Status survey and conservation action plans: International Union for the Conservation of Nature, Gland.

Palomares, F., Rodríguez, A., Laffitte, R. \& Delibes, M. (1991) The status and distribution of the Iberian lynx
(Felis pardina) in Coto Doñana area, SW Spain. Biological Conservation 57, 159-169.

Palomares, F., Ferreras, P., Fedriani, J.M. \& Delibes, M. (1996) Spatial relationships between Iberian lynx and other carnivores in an area of south-western Spain. Journal of Applied Ecology 33, 5-13.

Patton, S. \& Rabinowitz, A. (1994) Felidae in Thailand: a coprological survey. Journal of Wildlife Diseases 30, 472-475.

Patton, S., Rabinowitz, A., Randolph, S. \& Strawbridge, S. (1986) A coprological survey of parasites of wild neotropical Felidae. Journal of Parasitology 72, 517-520.

Rodríguez, A. \& Carbonell, E. (1998) Gastrointestinal parasites of the Iberian lynx and other wild carnivores from central Spain. Acta Parasitologica 43, 128-136.

Roelke, M.E., Jacobson, E.R., Kollias, G.V. \& Forrester, D.J. (1985) Medical management and biomedical findings on the Florida panther, Felis concolor coryi, July 1, 1983 to June 30, 1985. Annual Report, Florida Game and Fresh Water Fish Commission, Gainesville, Florida.

Schad, G.A. \& Page, M.R. (1982) Ancylostoma caninum: adult worm removal, corticosteroid treatment, and resumed development of arrested larvae in dogs. Experimental Parasitology 54, 303.

Shaw, D.J. \& Dobson, A.P. (1995) Patterns of macroparasite abundance and aggregation in wildlife populations: a quantitative review. Parasitology 111, 111-127.

Siegel, S. (1970) Estadística no paramétrica. Ed. Trillas, S.A., México, D.F.

Smith, J.D., Addison, E.M., Smith, L.M. \& Quinn, N.M.S. (1985) Helminth parasites of Canada lynx (Felis canadensis) from northern Ontario. Canadian Journal of Zoology 64, 358-364.

SPSS Inc. (1999) SPSS for Windows.

Stone, J.E. \& Pence, D.B. (1978) Ecology of helminth parasitism in the bobcat from West Texas. Journal of Parasitology 64, 295-302.

Torres, J., García Perea, R., Gisbert, J. \& Feliú, C. (1998) Helminth fauna of the Iberian lynx, Lynx pardinus. Journal of Helminthology 72, 221-226.

Watson, T.G., Nettles, V.F. \& Davidson, R. (1981) Endoparasites and selected infectious agents in bobcats (Felis rufus) from West Virginia and Georgia. Journal of Wildlife Diseases 17, 547-554.

(Accepted 12 September 2003) (C) CAB International, 2004 